\title{
A educação financeira como política pública no Brasil e seus potenciais impactos no
}

\section{orçamento familiar}

\author{
Financial education as a public policy in Brazil and its potential impacts on the family budget \\ La educación financiera como política pública en Brasil y sus potenciales impactos en el
}

presupuesto familiar

Recebido: 13/07/2021 | Revisado: 19/07/2021 | Aceito: 22/07/2021 | Publicado: 29/07/2021

\author{
Quetsia Dantas Magalhães Ribeiro \\ ORCID: https://orcid.org/0000-0003-1970-2531 \\ Universidade Federal dos Vales do Jequitinhonha e Mucuri, Brasil \\ E-mail: quetsia.dantas@ufvjm.edu.br \\ Márcio Coutinho de Souza \\ ORCID: https://orcid.org/0000-0002-4238-1572 \\ Universidade Federal dos Vales do Jequitinhonha e Mucuri, Brasil \\ E-mail: marcio.souza@ufvjm.edu.br \\ Naldeir dos Santos Vieira \\ ORCID: https://orcid.org/0000-0001-5624-8345 \\ Universidade Federal dos Vales do Jequitinhonha e Mucuri, Brasil \\ E-mail: naldeir.vieira@ufvjm.edu.br \\ Raquel Cristina Lucas Mota \\ ORCID: https://orcid.org/0000-0003-1543-4306 \\ Universidade Federal dos Vales do Jequitinhonha e Mucuri, Brasil \\ E-mail: raquel.lucasmota@ufvjm.edu.br
}

\begin{abstract}
Resumo:
O Decreto Federal n. 7.397, de 22 de dezembro de 2010, formalizou as diretrizes básicas de educação financeira no Brasil. A partir das diretrizes estabelecidas foram criados projetos sobre educação financeira a fim de viabilizar a política pública sobre o tema no Brasil. Assim, o objetivo deste artigo é refletir sobre a educação financeira como política pública no Brasil, analisando se a existência de projetos que atendam as diretrizes básicas de educação financeira promovem a conscientização para a otimização do orçamento das famílias brasileiras. Por meio de resultados de pesquisas publicadas em sites oficiais do governo federal brasileiro e em revistas científicas que abordem a temática, realizou-se uma pesquisa qualitativa de natureza teórica. Os resultados mostram que embora haja necessidade de a educação financeira ser tratada como política pública, os projetos advindos das diretrizes previstas na legislação não são capazes de promover, por si só, mudanças diretas no comportamento individual no que se refere aos cuidados com o orçamento familiar.
\end{abstract}

Palavras-chave: Educação Financeira; Política Pública; Orçamento familiar.

\begin{abstract}
Federal Decree n. 7397, of December 22, 2010, formalized the basic guidelines for financial education in Brazil. Based on the established guidelines, projects on financial education were created in order to make public policy on the subject in Brazil feasible. Thus, the purpose of this article is to reflect on financial education as a public policy in Brazil, analyzing whether the existence of projects that meet the basic guidelines of financial education promote awareness for optimizing the budget of Brazilian families. Through research results published on official websites of the Brazilian federal government and in scientific journals that address the subject, a qualitative theoretical research was carried out. The results show that although there is a need for financial education to be treated as a public policy, the projects arising from the guidelines provided for in the legislation are not capable of promoting, by themselves, direct changes in individual behavior with regard to care for the family budget.
\end{abstract}

Keywords: Financial Education; Public policy; Family budget.

\section{Resumen}

Decreto Federal n. 7397, del 22 de diciembre de 2010, formalizó los lineamientos básicos para la educación financiera en Brasil. Con base en los lineamientos establecidos, se crearon proyectos de educación financiera para viabilizar las políticas públicas sobre el tema en Brasil. Así, el propósito de este artículo es reflexionar sobre la educación financiera como política pública en Brasil, analizando si la existencia de proyectos que cumplen con los lineamientos básicos de la educación financiera promueven la conciencia para la optimización del presupuesto de las familias brasileñas. A través de resultados de investigación publicados en sitios web oficiales del gobierno federal brasileño y 
en revistas científicas que abordan el tema, se realizó una investigación teórica cualitativa. Los resultados muestran que si bien existe la necesidad de que la educación financiera sea tratada como una política pública, los proyectos que surgen de los lineamientos previstos en la legislación no son capaces de promover, por sí mismos, cambios directos en el comportamiento de las personas en materia de atención a la salud. el presupuesto familiar.

Palabras clave: Educación Financiera; Política pública; Presupuesto familiar.

\section{Introdução}

A educação financeira é um tema relativamente novo no âmbito da literatura científica brasileira. No ano de 2010, por meio de Decreto Federal, foram instituídas as diretrizes básicas de educação financeira no Brasil (Brasil, 2010). A partir disso, foram iniciados projetos com vistas a cumprir as diretrizes outrora estabelecidas. Assim, iniciou-se o processo de transformação quanto ao tema até então distante e pouco conhecido pela sociedade brasileira.

A educação financeira tem o potencial para proporcionar aos indivíduos melhor conhecimento a respeito do orçamento familiar com vistas a promover maior equilíbrio no uso dos recursos disponíveis. Da perspectiva de Brito et al. (2012), alguns estudos demonstram que fatores como superendividamento, ausência de conhecimento sobre serviços bancários e oferta de crédito evidenciam a necessidade de ações voltadas para a educação financeira.

Além disso, quando vista como um problema, a temática precisa ser colocada em destaque com fluxos de alternativas e vontade governamental para ser tratada como política pública (Capella, 2007). Assim, as medidas encontradas como solução para o problema podem se tornar eficazes. Isso porque, maiores investimentos em educação financeira da população em geral podem refletir em maior conscientização sobre o tema, alterando alguns comportamentos que podem levar a endividamentos desnecessários.

Por essa razão, ao considerar que a educação financeira no Brasil deva ser tratada como uma política pública, sobretudo, à luz dos modelos de múltiplos fluxos desenvolvidos por Kingdon (2003), torna-se relevante refletir se o estabelecimento de diretrizes sobre educação financeira no Brasil e os projetos dela decorrentes são suficientes para compor o fluxo de alternativas para o melhor uso dos recursos financeiro obtidos pelos cidadãos.

Isso porque existem registros de vários projetos voltados para a educação financeira que buscam promover conscientização da população sobre o tema e também há finalidade precípua de atender as diretrizes básicas propostas em norma federal (Vida e Dinheiro, 2021). Contudo, os resultados das pesquisas desenvolvidas pelo Governo Federal no setor de endividamento das famílias brasileiras demonstram que esse endividamento tem crescido (Peic \& Cnc, 2021).

Nesse contexto, propõe-se a seguinte questão direcionadora deste trabalho: os projetos desenvolvidos para atender as diretrizes básicas da educação financeira no Brasil são suficientes para mitigar o problema da gestão indevida do orçamento familiar por parte do público alvo?

Em decorrência, o objetivo deste artigo é analisar se a educação financeira é fomentada por meio de política pública no Brasil e se a existência de projetos que atendam as diretrizes básicas de educação financeira no Brasil promove mudanças comportamentais nas famílias brasileiras, tendo em vistas a melhor gestão do orçamento familiar.

\section{Metodologia}

Para alcançar o objetivo do trabalho, optou-se por realizar a pesquisa de natureza qualitativa com a utilização do método de revisão bibliográfica. A pesquisa qualitativa, embora detenha diferentes significados no campo das ciências sociais, compreende um conjunto de diferentes técnicas interpretativas e tem por objetivo demonstrar o sentido dos fenômenos no mundo social (Neves, 1996). Nesse aspecto, no método qualitativo é relevante a interpretação por parte do pesquisador sobre o fenômeno em estudo (Pereira, et al, 2018), com a finalidade de atender a questão central proposta. A revisão bibliográfica tem como objetivo desenvolver o estudo a partir de produções na literatura já existentes sobre determinado tema (Gil, 2002). O 
artigo tem caráter exploratório, isto é, propõe explorar conceitos, ideias e os resultados de pesquisas realizadas pelo Governo Federal em parcerias disponíveis nos sites oficiais.

De início, foi necessário realizar uma revisão bibliográfica sobre o tema educação financeira, seu conceito e sua relevância. Para tanto, foi realizado um levantamento do estado da arte do tema a partir da consulta a banco de dados em revistas científicas, anais de eventos científicos. No campo de busca foram inseridos os termos "educação financeira" e "políticas públicas". Não houve um marco temporal previamente estabelecido para ano das publicações a serem identificadas. Como critérios de inclusão dos trabalhos a serem selecionados para realização desse trabalho era necessário que os mesmos trouxessem conceitos relevantes a respeito do tema. Especificamente quanto ao tema "políticas públicas", o marco teórico principal foi desenvolvido a partir de livros clássicos sobre o assunto e complementados por publicações em artigos científicos.

Dos trabalhos a respeito de educação financeira, a revisão bibliográfica foi utilizada para construir o referencial teórico sobre o conceito de educação financeira e traçar seus principais aspectos de relevância com a finalidade de elucidar os motivos pelos quais o tema é relevante para o Brasil.

Com a finalidade de estabelecer um marco teórico para subsidiar a reflexão sobre a educação financeira como uma política pública, a revisão bibliográfica nas produções científicas sobre políticas públicas foi importante para identificar dois dos modelos principais a respeito de agendamento governamental que mentaliza, elabora e executa determinada política pública.

Nesse momento, diante da construção desses dois marcos teórico, foi possível proporcionar a reflexão de que a educação financeira deve ser tratada como política pública, uma vez que ambos os modelos desenvolvidos por Kingdon (2003) e Frank Baumgartner e Brian Jones (1993), respectivamente conseguem enquadrar o problema sobre educação financeira no país com outros fatores de convergência.

Por outro lado, ao considerar a educação financeira como política pública, ainda é necessário refletir se o fluxo de alternativas (Kigndon, 2003) para a solução do problema foi suficiente para alterar o comportamento familiar frente ao cuidado com a finança pessoal. Assim, para atender essa segunda parte foi identificada os sites do Governo Federal específicos sobre o assunto, quais sejam: Portal de Comércio do Brasil, Vida e Dinheiro e CDL Brasil.org.

Em ambos os sites foi colocado na aba "pesquisar" a terminologia "pesquisas". Assim, os sites apresentam todas as pesquisas que foram realizadas. Em relação ao site Vida e Dinheiro, foi possível ter acesso aos relatórios dos mapeamentos realizados em 2013 e em 2018 dos projetos que surgiram com o objetivo de atenderem as diretrizes de educação financeira no país. Esses relatórios foram baixados em arquivos PDF e os resultados foram coletados para apresentação nesse trabalho. Como critérios de seleção dos resultados, foi utilizado os dados mais relevantes destacados pela própria pesquisa. Não foram analisados resultados secundários dessas pesquisas.

Quanto ao site Portal de Comércio do Brasil e Peic também foi colocado no termo de busca o descritor [pesquisas] na categoria do filtro existente na página inicial do site. Como resultado, são apresentadas todas as pesquisas realizadas no setor, mas os resultados selecionados foram as pesquisas denominadas como "Pesquisa de Endividamento e Inadimplência do Consumidor (Peic)". Para cada um desses resultados há a opção de escolha do ano o qual será analisado. Desse modo, foram utilizadas as pesquisas dos anos de 2013/2014; 2017/2018 e 2020/2021. Pontualmente, para ter acesso ao resultado do ano de 2021, foi analisada a notícia sobre o aumento do número de endividados.

Nas pesquisas acima mencionadas é possível acessar por meio de links a própria análise realizada, os gráficos e a série histórica da pesquisa. Para esse trabalho, foram baixados todos os arquivos de acesso de análise. Os dados mais relevantes destacados no próprio relatório foram utilizados nesse artigo.

Por fim, ao pesquisar no banco de dados de forma mais específicas os assuntos sobre educação financeira e pesquisa, foi apresentado o trabalho desenvolvido pelo CDL Brasil junto ao Banco Central e outros parceiros. Disponível no site da CDL 
Brasil, o resultado foi capaz de demonstrar os fatores que não colaboram com a ausência de cuidado perante o orçamento familiar.

A partir dessas informações e do marco teórico estabelecido foi possível propiciar uma discussão capaz de responder a questão central proposta nesse artigo. Portanto, a elaboração desse trabalho pode ser classificada nas seguintes fases: i) levantamento bibliográfico; ii) levantamento dos sites oficiais do governo federal que versem sobre educação financeira; iii) identificação de pesquisas divulgadas em sites oficiais também associado ao tema sobre educação financeira; iv) construção de referencial teórico para proporcionar embasamento à análise a ser feita e v) apresentação dos resultados com consequente discussão.

\section{Referencial Teórico}

Nessa seção será discutido sobre o conceito da educação financeira e sua relevância no Brasil e as concepções de políticas públicas no Brasil.

\subsection{Conceito de educação financeira e sua relevância no Brasil}

O início das discussões sobre educação financeira no Brasil começou após a segunda metade do século XX e início do século XXI e, a cada ano, a produção literária acerca do tema tem aumentado, ainda que o assunto seja tratado de forma genérica. Tratando-se da sua definição, também não há um conceito fechado, de modo que a educação financeira pode ser considerada uma modalidade de transmissão de conhecimento em que os interessados passam a desenvolver habilidades que os permitem tomar decisões seguras, melhorando o gerenciamento de suas finanças pessoais (Savoia, Sato \& Santana, 2007). Pode ser definido também como um processo de aprendizagem dos indivíduos quanto às finanças pessoais que passam a adquirir uma visão crítica sobre o uso do dinheiro (Cordeiro, Costa, \& Silva, 2018).

A Organização para a Cooperação e Desenvolvimento Econômico (OCDE) é uma organização econômica intergovernamental com trinta e sete países membros - países da América Latina e do Caribe, fundada em 1961 para estimular o progresso econômico e o comércio mundial com o diálogo sobre disseminação de boas práticas em áreas como a educação.

Para a OCDE a educação financeira é um processo em que indivíduos passam a aprimorar conhecimentos a respeito de conceitos e produtos e assim passam a desenvolver técnicas que contribuem para aproveitamento das oportunidades financeiras, entendendo melhor seus riscos. Assim, os indivíduos compreendem como fazer um bom uso do dinheiro e passam a tomar decisões conscientes e sustentáveis financeiramente (Scopel \& Santos, 2020).

Outro sentido ao conceito é a perspectiva da educação financeira voltada para ações financeiras e seu conjunto de atividades. Isto é, àquele que sabe como realizar o controle das despesas diárias, manuseio do cartão de crédito, financiamento ou empréstimos a ponto de que esse conhecimento proporcione melhor escolha por parte do indivíduo (Cordeiro, et al., 2018). Além disso, a ausência de controle sobre as finanças é resultado da ausência de planejamento e informação devida, uma vez que saber elaborar e controlar orçamentos são fatores importantes para a saúde financeira pessoal e familiar (Silva, et al., 2019; Leite, 2017).

Embora haja distintos conceitos, notam-se elementos em comum quanto à definição sobre a educação financeira. Ferreira (2017) define que a capacidade dos indivíduos de fazer escolhas inteligentes, em razão de um processo de conhecimento, em relação ao uso e a gestão do dinheiro são características comuns dos conceitos sobre educação financeira.

O cidadão devidamente instruído financeiramente é capaz de ter participação ativa na economia e colabora com um mercado cada vez mais competitivo (Cruz, et al., 2020). Nesse cenário, a importância da educação financeira possui duas principais perspectivas, quais sejam: i) a perspectiva do bem estar pessoal em que os indivíduos possam tomar decisões financeiras adequadas sem comprometer negativamente o futuro; ii) a perspectiva do bem estar da sociedade, vez que existindo 
sujeitos capacitados, fortalece a autorregulamentação do mercado e, portanto, minimiza estratégicas de regulamentação e proteção ao consumidor financeiro (Lucci, et al., 2010). Além disso, por meio da educação financeira pode-se alcançar o equilíbrio das finanças pessoais, o preparo para futuros imprevistos (Scopel \& Santos, 2020).

Ainda, existem três variáveis que explicitam a relevância da educação financeira. São elas: disponibilidade do crédito, superendividamento em razão do consumo e diversidade em serviços bancários (Brito, et al., 2012). Quando há disponibilidade do crédito, significa que, em geral, a economia do país se encontra mais estável (Brito, et al., 2012). Assim, é preciso conscientizar o indivíduo quanto às características do crédito (prazos, taxas, limites, juros) para que o mesmo seja mais bem aproveitado. Dessa forma, possibilitar a educação financeira torna-se essencial para que esses elementos sejam utilizados dentro do planejamento financeiro do indivíduo ou da sua família (Savoia, et al., 2007).

O superendividamento ou endividamento que decorre do consumo desenfreado é deflagrado, dentre outros fatores, por meio de mídias de marketing que colaboram com o incentivo excessivo de ofertas, tanto de serviços como de produtos. Quando os indivíduos não detêm práticas de educação financeira, há o comprometimento de seus recursos com objetos frutos de um desejo passageiro. Com recursos comprometidos, os indivíduos podem se colocar em situações de superendividamento. Nesse ponto, a educação financeira pessoal proporcionaria maior consciência do uso correto dos recursos disponíveis (Brito, et al., 2012).

Por fim, o excesso de serviços bancários leva o consumidor a inúmeras oportunidades de investimento, mas em geral as pessoas não possuem conhecimentos básicos para identificar o melhor investimento frente ao binômio possibilidade necessidade. Em decorrência disso, os inúmeros serviços ou produtos financeiros podem acarretar a contratação equivocada ou precipitada do indivíduo quando não devidamente educado financeiramente (Brito, et al., 2012).

A partir dessas variáveis acima expostas, nota-se uma crescente necessidade de implementação da política de educação específica na área financeira para que, ao final, o sucesso do desenvolvimento dessa política resulte no aumento do bem estar e da qualidade de vida dos indivíduos (Brito, et al., 2012).

$\mathrm{O}$ argumento principal em defesa da educação financeira é de que ela impulsionaria a capacitação financeira das famílias, por meio da transferência de conhecimentos e informações sobre o correto gerenciamento das finanças pessoais, e também sobre o uso da variedade de oferta de produtos e serviços financeiros disponíveis no mercado. Dentro dessa ótica, a educação financeira, ao empoderar o cidadão, fortalece a autorregulamentação de mercado e, portanto, minimiza (ou mesmo dispensa) estratégias de regulamentação e proteção ao consumidor financeiro (Pereira, et al., 2019).

\subsection{Concepções de políticas públicas no Brasil}

Realizada as considerações a respeito do conceito e da importância sobre educação financeira no Brasil, é necessário refletir ainda a respeito do desenvolvimento de uma política pública no Brasil sobre o tema.

De início, não existe um conceito único a respeito do que são políticas públicas. Na produção científica brasileira, o debate sobre o tema iniciou em meados do século XX e ainda é incipiente nas pesquisas, mas desde 1940 existem alguns conceitos importantes, conforme Quadro 1. 
Quadro 1 - Conceitos de Políticas Públicas no Brasil.

\begin{tabular}{|c|l|}
\hline AUTOR & \multicolumn{1}{c|}{ CONCEITO } \\
\hline Laswell (1943) & $\begin{array}{l}\text { Política pública ocorre quando se responde as seguintes questões: quem ganha o quê, por } \\
\text { quê e que diferença faz. }\end{array}$ \\
\hline Lynn (1980) & Conjunto de ações do governo que produzirão efeitos específicos. \\
\hline Dye (1984) & Aquilo que o governo escolhe entre fazer ou não fazer. \\
\hline Peters (1986) & $\begin{array}{l}\text { Conjunto de atividades dos governos que agem diretamente ou por meio de delegação e que } \\
\text { influenciam a vida dos cidadãos. }\end{array}$ \\
\hline Mead (1995) & $\begin{array}{l}\text { Um campo contido no estudo sobre política que analisa o governo à luz de grandes questões } \\
\text { públicas. }\end{array}$ \\
\hline
\end{tabular}

Fonte: Baseado em Souza (2006).

Os conceitos sobre política pública destacados no Quadro 1 são de maior destaque na literatura. No entanto, o conceito mais conhecido é o proposto por Leswell (1943) que além de defini-la também analisa o ciclo das políticas públicas (Souza, 2006).

Os conceitos postos no Quadro 1 também sofreram algumas críticas, pois consideram apenas os aspectos procedimentais da realização de determinada política pública e não refletem sobre o embate em torno de ideias e interesses. Os críticos também apontam que esses conceitos não abordam sobre as limitações e impactos da decisão dos governos, como se apenas bastasse à decisão de tão somente aplicar a política pública em determinado território. Não menos importante, se critica ainda o fato de centralizar o governo como o único ator de idealização e execução de políticas públicas sem considerar a possibilidade de realizá-las por meio de ou junto com outros atores sociais (Souza, 2006).

Sendo assim, Souza (2006, p. 26) propõe que política pública pode ser resumida em um campo de conhecimento que procura de forma concomitante “colocar o governo em ação e/ou analisar essa ação (variável independente) e, quando necessário, propor mudança no rumo ou curso dessas ações (variável dependente)".

Do ponto de vista teórico, existem dois modelos essenciais sobre como a política pública pode ser definida no agendamento do governo, quais sejam: o modelo de múltiplos fluxos (multiple streams model) desenvolvido por John Kingdon (2003) e o modelo de equilíbrio pontuado (punctuated equilibrium model) de Frank Baumgartner e Brian Jones (1993) (Capella, 2007).

O modelo desenvolvido por Kingdon (2003) procura responder a seguinte questão: "por que alguns problemas se tornam importantes para um governo?’. Para tanto, o teórico considera as políticas públicas como um conjunto formado por quatro processos: o estabelecimento de uma agenda de políticas públicas; a consideração das alternativas para a formulação de políticas públicas; a escolha dominante entre o conjunto de alternativas disponíveis e a implementação da decisão (Capella, 2007).

Nesse modelo, o governo só adequa a agenda governamental quando há a convergência de três fluxos: problema, soluções ou alternativas e política. Isso porque, muitos são os problemas de determinada sociedade, mas nem todos se destacam quando da idealização de determinada política pública para resolvê-lo ou mitigá-lo. Assim, no modelo de Kingdon (2003) identifica-se um problema quando indicadores demonstram determinada magnitude de uma situação, haja ocorrência de eventos ou crises e quando ocorre um feedback proveniente do monitoramento de programas desenvolvidos pelo governo (Gottems, et al., 2013; Capella, 2007).

Uma vez identificado o problema, pensa-se em alternativas para solucioná-los. Todavia, essas alternativas precisam de viabilidade técnica para ser executadas com custos toleráveis e determinada aceitação pela própria comunidade. Após, considera-se o elemento da política. Isso significa que é preciso forças políticas organizacionais e mudanças no governo para proporcionar oportunidade de mudanças que ocorrerá efetivamente quando houver convergência dos três fluxos acima 
expostos (Capella, 2007). Cabe destacar que os fluxos "problema-soluções/alternativas-política" não constituem um processeo sequencial e ordenado, podendo ser interligados quando há um ambiente propício para a mudança política (Gottems, et al., 2013).

Por outro lado, o modelo de equilíbrio pontuado, desenvolvido por Baumgartner e Jones (1993), demonstra que para lidar com uma diversidade de questões políticas, os governos delegam autoridade a agentes especializados em uma determinada área. Esses agentes com legisladores e grupos de interesses formam subgrupos que discutem paralelamente vários temas distintos e dessa forma constroem uma imagem da política que ajuda a manter o status quo denominada monopólio (Capella, 2007). Trata-se da chamada "policy image", ou seja, de ideias que sustentam o arranjo institucional onde permitem que o entendimento sobre a política seja compreendido por uma comunidade de forma simples e direta, contribuindo para a disseminação das questões (Almeida \& Gomes, 2017).

Quando há divergência em relação ao entendimento até então uniformizado acerca daquela política, os oponentes passam e podem se concentrar em um conjunto diferente de imagens que pode levar ao colapso do monopólio. Para que o problema chame atenção do governo é preciso que uma imagem a seu respeito efetue uma ligação com a possível solução e assim ocorre a oportunidade de mudança do status quo que faça o governo tomar decisões a fim de estabelecer alternativas de soluções para o novo cenário (Almeida \& Gomes, 2017; Silvestre \& Araújo, 2015; Capella, 2017).

Para Souza (2006), a formulação de políticas públicas se concretiza no estágio em que os governos democráticos explanam seus propósitos eleitorais em programas e ações que produzirão resultados ou mudanças no mundo real. Os modelos teóricos sobre políticas públicas não se esgotam no presente trabalho que propõe um referencial elementar a respeito do tema com a finalidade de utilizar o recorte necessário à reflexão desse estudo.

Desse modo, ao considerar as perspectivas de Kingdon (2003) e de Baumgartner e Jones (1993) quanto às políticas públicas, passa a ser possível propiciar a discussão sobre o tratamento da educação financeira do Brasil como tal e seus potenciais impactos. Tudo isso, a partir da análise de resultados de pesquisas já realizadas pelo Governo Federal do Brasil com empresas parceiras.

\section{Resultados de Análise de Pesquisas}

Essa seção abordará as iniciativas nacionais para mobilizar estratégias de educação financeira no Brasil e as análises de pesquisas em 2013/2014 e 2017/2018 e cenário atual (2020-2021) da situação das famílias brasileiras em relação ao endividamento.

\subsection{Iniciativas nacionais para mobilizar estratégias de educação financeira no Brasil}

No Brasil, a primeira medida legislativa para tratar sobre ações específicas ao combate a ausência de educação financeira, com a finalidade de fomentar cidadãos a tomar decisões com os próprios recursos financeiros foi o Decreto Federal n. 7.397 de 22 de dezembro de 2010. Revogado 10 anos depois pelo Decreto Federal 10.393 de 09 de junho de 2020, tem-se que a nova legislação institui a nova Estratégia Nacional de Educação Financeira (ENEF) que objetiva promover educação financeira, securitária, previdenciária no País (Brasil, 2020).

Em razão disso, é reacendida a possibilidades de novas propostas de medidas que visam combater a ausência de educação financeira para a população em geral no Brasil. Essas têm recebido apoio de instituições financeiras, autoridades governamentais, instituições acadêmicas e de pesquisa e fundações e entidades do terceiro setor, mas estudos no sentido de verificar o desdobramento dessas iniciativas ainda são embrionários (Pereira, et al., 2019).

O site federal e oficial brasileiro de educação financeira é denominado Vida e Dinheiro sendo administrado pela Associação de Educação Financeira (AEF), uma organização da sociedade civil de interesse público cuja criação do domínio 
faz parte das estratégias de educação financeira no Brasil (Saraiva, 2017). Referidas estratégias possuíram participação de instituições ligadas ao mercado e funcionam como ferramentas para que o brasileiro passe a se adaptar ao capitalismo, isto é, tenha condições de planejar ações individuais que o beneficie no mercado. Embora haja um novo Decreto Federal (2020) com a instituição de nova estratégia nacional de educação financeira, o Decreto Federal do ano de 2010 possibilitou algumas estratégias que não podem ser desconsideradas nesse trabalho.

No ano de 2009 foi realizado um estudo preliminar a respeito das iniciativas sobre educação financeira no Brasil cujo resultado foi a identificação de 64 iniciativas, projeto patrocinado pela empresa Serasa. Com o advento do Decreto Federal n 7.397/10 e em razão da pesquisa preliminar em 2009, ocorreu no ano de 2013, o Primeiro mapeamento nacional das iniciativas de Educação Financeira no Brasil, um projeto desenvolvido pelo ENEF que teve como objetivo levantar informações mais profundas a respeito dos projetos existentes no país.

De acordo com o relatório estatístico do ENEF, realizado no ano de 2013 e publicado no site governamental, foram identificadas 803 iniciativas em educação financeira no Brasil, porém apenas 317 completaram o cadastro no site. Dessas iniciativas devidamente registradas no site, tem-se que $60 \%$ delas foram realizadas de forma gratuita e $8 \%$ de forma exclusivamente paga. Quanto às iniciativas regionalizadas, as regiões sul e sudeste se destacaram (ENEF, 2013).

Dos projetos sobre educação financeira no ano de 2013, 60\% atenderam as pessoas físicas, 39\% as pessoas físicas e jurídicas e apenas $1 \%$ atenderam pessoas jurídicas de forma exclusiva. Ainda em 2013, o relatório demonstrou que a faixa etária dos beneficiários atingidos pelas iniciativas eram jovens entre 19 a 29 anos e adultos (30 a 59 anos) com 45\% e 42\%, respectivamente.

A formação educacional dos beneficiários dos projetos se concentra naqueles que possuem ensino médio e superior, demonstrando que no ano de 2013 os projetos de educação financeira não atingiam grande parte do ensino fundamental, sendo que apenas $36 \%$ das crianças e adolescentes obtiveram acesso aos projetos sobre educação financeira. Nesse ponto, Saraiva (2017) destaca que a pesquisa divulgada no site governamental demonstra a ausência de maior envolvimento dos setores educacionais em relação à temática, sobretudo, quanto às estratégias coletivas de conscientização a respeito do tema.

Já no ano de 2018, ainda sob a vigência do Decreto Federal $n^{\circ} 7.397 / 10$, foi realizado o segundo mapeamento nacional e também foi publicado no site Vida e Dinheiro o relatório estatístico do ENEF do ano de 2018. Foram mapeados $72 \%$ a mais de iniciativas quando comparado com o primeiro mapeamento, ao passo que foram contabilizadas 1.383 iniciativas com 526 delas devidamente registradas no site em razão do cadastro completo.

O aumento das iniciativas citadas ocorreu em razão de maior participação das instituições escolares que, diferentemente dos anos anteriores, se destacou no segundo mapeamento. Em 2018 as iniciativas digitais foram uma novidade quando comparada ao ano de 2013 que não registra dados sobre projetos digitais. Isso porque 69\% das iniciativas ocorreram por meio de site, seguidas de 53\% delas apresentadas por redes sociais como facebook e twitter. Além disso, em 2018, 90\% das iniciativas foram registradas em instituições públicas de ensino, sendo que $78 \%$ delas foram ofertadas pelas escolas públicas enquanto as instituições privadas ofertaram apenas $7 \%$ desses projetos.

Diferente do ano de 2013, o segundo mapeamento (2018) indica a região norte do Brasil como aquela com mais iniciativas mapeadas em razão da alta presença de projetos nas escolas do estado do Tocantins. No ano de 2018 houve um aumento de $8 \%$ comparado ao ano de 2013 em relação às iniciativas ofertadas exclusivamente às pessoas jurídicas.

Quanto ao perfil do público, tem-se que em razão da maior participação escolar, a participação de crianças e adolescentes como público alvo dos projetos no ano de 2018 cresceu exponencialmente, atingindo juntos 65\% da participação, o que resultou na diminuição da participação de jovens e adultos. Em nível nacional, não foi identificado qual o maior público alvo das ações desenvolvidas, mas sugere-se que o público mais vulnerável seja destinatário dessas iniciativas (ENEF, 2019). 
Nota-se que no período de 5 anos entre os mapeamentos houveram muitas mudanças, com destaque a participação escolar, o que coloca em voga cada vez mais a necessidade de instituição da educação financeira na grade curricular dos espaços de ensino, como também a inovação quanto aos projetos desenvolvidos pelo meio digital capazes de um acesso mais democrático quando comparado a projetos que exigem a presença do participante.

Desse modo, existe no Brasil um plano de estratégico de fomento à educação financeira, mas nota-se que o assunto ainda é embrionário, sendo que apenas nos últimos 10 anos foi possível destacar atividades mais concretas nesse sentido. Lado outro, não é possível precisar em qual grau os projetos elucidados nos mapeamentos são capazes de transformar a comunidade as quais estão inseridos e, sobretudo, como as iniciativas refletem na vida do brasileiro.

Por outro lado, ao utilizar o recorte teórico baseado em Kingdon (2003), é possível vislumbrar os processos de agendamento governamental quanto ao tema. Isso porque a evidência do problema de ausência de educação financeira se destacou e as alternativas para solução do problema convergiu com o "humor nacional" - como cita Capella (2007) - que instituiu diretrizes educacionais por meio de decreto federal, cuja execução se deu no âmbito nacional com feedback de resultados a respeito das iniciativas, conforme os mapeamentos.

\subsection{Análises de pesquisas em 2013/2014 e 2017/2018 e cenário atual (2020-2021) da situação das famílias brasileiras em relação ao endividamento}

A Pesquisa de Endividamento e Inadimplência do Consumidor (Peic), realizada pela Confederação Nacional do Comércio de Bens, Serviços e Turismo (CNC) divulgado no Portal de Comércio do Brasil, site oficial, tem como objetivo investigar e acompanhar a condição de endividamento e inadimplência das famílias brasileiras. Por endividamento, a pesquisa utiliza o recorte da relação entre o valor atual das dívidas das famílias e o Sistema Financeiro Nacional. Os resultados são divulgados periodicamente, o que permite estabelecer comparativos entre os períodos.

Assim, considerando os mapeamentos realizados pelo ENEF, em parceria com a Serasa, a respeito das estratégias desenvolvidas para implementação da educação financeira, torna-se relevante verificar a situação de endividamento das famílias brasileiras nos períodos dos mapeamentos e no período atual a fim de estabelecer as discussões.

No ano de 2013, das famílias que foram entrevistadas, o percentual daquelas endividadas foi de 62,5\%. Em 2014 o quantitativo de famílias com dívidas caiu para 61,9\%, o menor patamar desde 2010. Contudo, o percentual de famílias que declararam não ter condições de quitar com seus débitos teve a menor taxa histórica de 5,4\% famílias em outubro de 2014. O uso do cartão de crédito e financiamentos foram as principais causas do endividamento em 2014.

Em dezembro do ano de 2018, a pesquisa desenvolvida pelo Peic/CNC apresenta que 59,8\% do total de famílias entrevistadas possuíam dívidas. Isso significa um percentual menor, quando comparado ao mesmo período do ano de 2017, quando 62,2\% eram o total das famílias endividadas. Em contrapartida, nesse ano de 2018, foi registrado o percentual de 9,2\% de pessoas que declararam não ter condições de pagar as dívidas e assim continuariam inadimplentes, o que também demonstra redução quando comparada ao ano de 2017, quando 9,7\% das famílias permaneceriam sem condições de arcar com as dívidas que detinham.

No ano de 2020, a pesquisa da Peic/CNC, evidenciou que o endividamento do brasileiro atingiu, em dezembro, o percentual de 66, 3\% enquanto que no mesmo período do ano anterior (2019), o endividamento era de 65,6\%. Desses endividados, em dezembro de 2020, o percentual de 11,2\% das famílias não teria condições de pagar, o que também aumentou quando comparado a porcentagem do mês dezembro/2019 (10\%).

No ano de 2021, no mês de fevereiro, $67,5 \%$ do total de famílias entrevistadas relataram que possuem dívidas. No mesmo mês do corrente ano, 10,5\% das famílias não tinham condições de pagar as dívidas. O relato das famílias é que as dívidas se tratam de cheque pré-datado, cartão de crédito, cheque especial, crédito consignado, empréstimo pessoal, prestação 
de carro e casa $(\mathrm{CNC}, 2021)$. Nesse sentido, $80 \%$ das famílias indicam que o cartão de crédito é a maior fonte de endividamento delas (CNC, 2021).

A pesquisa desenvolvida pelo CNC considera que a pandemia COVID-19 e o atraso na vacinação impactaram neste desempenho negativo no primeiro trimestre do ano de 2021, trazendo incerteza sobre o retorno do aquecimento da economia. Nesse ponto, sugerem o crédito como ferramenta de recomposição da renda, mas consideram que as famílias entrevistadas estão temerosas em assumir novas obrigações creditícias.

O endividamento no Brasil atingiu a maior proporção da série histórica (CNC, 2021). Assim, o cenário brasileiro apresenta indicativos razoáveis diante da relação indivíduo e finanças, havendo necessidade de políticas mais incisivas a fim de contribuir com a melhora desse cenário.

Contudo, é importante destacar que, a pesquisa realizada pela Confederação Nacional de Dirigentes Lojistas (CNDL), SPC Brasil e o Banco Central do Brasil, no ano de 2019, identificou que 36\% dos brasileiros não realizam controle do orçamento mensal, enquanto $44 \%$ dos entrevistados estão ou estiveram com o nome negativado nos cadastros de inadimplência no último ano (Brasil, 2019). Quando há inscrição negativa do nome do consumidor nos cadastros de proteção ao crédito, existe um reflexo no superendividamento - variável mencionada no tópico 3.3 - que repercute na economia do país. Isso porque, essas pessoas são excluídas do mercado de consumo, perdem autonomia negocial e possuem menos projeção do plano de vida quando não encontram soluções para o problema (Oliveira, 2019).

Todavia, enquanto mais de $80 \%$ declara que conseguem pagar as contas do fim do mês, menos da metade não fazem reserva financeira com o valor que sobra (Brasil, 2019). O problema financeiro pode surgir pela falta da educação financeira, sobretudo por ausência de planejamento da despesa familiar (Araújo, et al., 2018). Nesse sentido, o principal motivo identificado pela pesquisa para que o brasileiro não faça o controle de orçamento mensal é a crença de que não é necessário anotar todas as despesas e entradas, acreditando ser apenas o controle mental suficiente (23\%) seguidos dos motivos de ausência de disciplina (18\%) e preguiça (12\%) (Brasil, 2019).

A pesquisa também apresentou que nos momentos de maior dificuldade financeira, os brasileiros realizaram cortes nos gastos com lazer para conseguirem quitar suas despesas mensais. Restrições para saídas a bares e restaurantes, como também pesquisas de preços dos produtos e serviços adquiridos foram medidas encontradas pelos brasileiros a fim de assegurarem o pagamento das dívidas básicas, sem prejuízo na redução de compras de itens considerados mais supérfluos, como vestuário e acessórios (Brasil, 2019). As medidas encontradas pelos brasileiros impactam diretamente a economia, diante do desaquecimento do mercado de compras. Pouco mais de $20 \%$ fizeram trabalhos alternativos, considerados "bicos", para auferir determinada renda extra (Brasil, 2019).

Com a pandemia do COVID-19, o cenário do brasileiro é incerto e o fator de despreparo para a gestão financeira pode ter contribuído para a ampliação dos efeitos do endividamento. Afinal, conforme a pesquisa realizada no ano de 2019, menos da metade dos brasileiros entrevistados realizam reserva financeira, sendo esta um dos princípios básicos da educação financeira, o que pode ter contribuído com o crescente índice de endividamento das famílias nos anos de 2020-2021.

\section{Discussão}

Após a apresentação do referencial teórico e dos resultados acima delineados, passa-se à discussão dos mesmos. As análises das pesquisas realizadas nos anos de 2013/2014, 2017/2018 e 2020-2021 pela Peic/CNC têm como intuito demonstrar a realidade de famílias quanto ao cuidado com o orçamento familiar. Para alcançar o objetivo desse artigo, é preciso confrontar os resultados das pesquisas promovidas pela Peic/CNC com o período de iniciativas que buscaram estratégias de desenvolvimento de educação financeira no Brasil para atender as diretrizes de educação financeira proposta em lei.

Ao partir do marco teórico apresentado no modelo de múltiplos fluxos desenvolvidos por Kingdon (2003), tem-se que 
inicialmente os indicativos apresentados nas pesquisas da Peic/CNC podem ser um dos elementos que contribuem com a identificação de um problema na sociedade. A variável superendividamento/endividamento possui determinada constância nas famílias brasileiras, com alteração significativa em relação às famílias que não tem condições e não irá quitar seus débitos. Contudo, como visto, não basta a existência do problema de forma isolada. É preciso convergência dos outros fatores. Desse modo, considerando as alternativas e a vontade política, pode se afirmar que o estabelecimento das Diretrizes de Educação Financeira por meio de decreto legislativo e posteriormente execução de projetos com vistas a implementar as iniciativas tem o condão de tratar a ausência de educação financeira como uma política pública.

Em contraponto, ao considerar o modelo de equilíbrio pontuado a situação de endividamento das famílias brasileiras, os resultados das pesquisas analisadas constituem uma nova "policy image", ao passo que oportuniza o olhar para essa questão após a quebra do status quo em que a sociedade se mantinha quando não se discutia sobre educação financeira no país.

Assim, vislumbra-se no primeiro momento a potência da educação financeira ser tratada como política pública no Brasil. Porém, ainda é preciso verificar se as alternativas encontradas pelo Governo Federal foram ou são suficientes para promover mudanças mais incisivas, sobretudo no âmbito do comportamento familiar frente ao cuidado com o orçamento.

Diante da análise dos resultados das pesquisas realizadas em 2013/2014 e 2017/2018, pôde-se observar que os percentuais de endividamento das famílias brasileiras foram menores em 2013/2014 e em 2017/2018 quando comparado aos anos 2020/2021. Nesses mesmos períodos foram realizados os mapeamentos das iniciativas de educação financeira no país, promovidos pelo ENEF. Nesse sentido há, em linha de princípio, o indicativo de que com o desenvolvimento dos projetos houve um aumento de conscientização das famílias quanto a educação financeira e essa conscientização pôde refletir nas organizações das finanças.

Para Brito et al. (2012), uma das variáveis que estimula a necessidade de educação financeira é o superendividamento ou endividamento. Nota-se, portanto, que no período em que o estímulo à educação financeira era maior por meio de projetos, o endividamento das famílias nesses mesmos anos era menor.

Em contrapartida, outra variável que estimula a educação financeira é o excesso de serviços bancários. Como visto, quando o indivíduo não sabe o que investir ou adquirir, suas escolhas podem se tornar prejudiciais. Nesse ponto, ainda que com a existência de projetos de estímulos sobre educação financeira, nota-se que tais não refletiram no poder de escolha dos indivíduos, uma vez que as maiores fontes de endividamento permaneceram sendo o cartão de crédito, financiamentos e empréstimos.

Ainda é importante destacar que os mapeamentos dos anos de 2013 e 2018 foram baseados em iniciativas que visavam atender as diretrizes de educação financeira propostas pelo Decreto Federal no 7.397/2010. Desde o Decreto Federal ${ }^{\circ}$ 10.393/2020 que estabelece as novas diretrizes básicas de educação financeira no país não há registros do mapeamento dos projetos/iniciativas que foram realizados ou mantidos após a nova legislação.

Por outro lado, as pesquisas da Peic/CNC demonstraram que o período de 2020-2021 registrou aumentos significativos do número de famílias endividadas e também no número delas que não vão arcar com as dívidas e seguirão inadimplentes. Esses resultados são diferentes dos resultados encontrados nas pesquisas dos anos 2013/2014 e 2017/2018. Convergente a isso, não houve mapeamentos de projetos desenvolvidos no Brasil acerca do assunto após o Decreto Federal 10.393/2020. Em 2020 e 2021, o aumento de percentual de famílias endividadas foi de, respectivamente, 3,8\% e 4,9\%; 5\% e $5,6 \%$ a mais, quando comparado com os anos de 2013 e 2014. Ao comparar o endividamento das famílias brasileiras em 2020 e 2021 com os anos 2017 e 2018, também há um aumento de 6,3\%, 4,1\%; 7,7\% e 5,3\%, respectivamente.

Todavia, não se pode atribuir os reflexos do superendividamento à completa ausência de iniciativas que contribuam com a propagação sobre educação financeira a partir do ano de 2020. Também não é possível determinar que a existência dos projetos nos anos de 2013 e 2018 foram fatores que por si só refletiram nos índices menores de superendividamento nas 
famílias, embora seja um indicativo. Isso porque, conforme a pesquisa realizada em 2019 pela CDL em parceria com o Banco Central, as pessoas não realizam reserva financeira e nem o controle efetivo de gastos por diversos fatores como ausência de necessidade em achar que precisa de uma planilha para realizar tal atividade ou até mesmo por preguiça, por exemplo.

Essa última pesquisa é um contraponto necessário, pois foi realizada após os mapeamentos dos anos de 2013 e 2018. Isso pode significar que mesmo que membros dessas famílias tenham tido acesso aos projetos registrados nos mapeamentos, a mudança comportamental no âmbito familiar quanto ao cuidado com o orçamento não se efetiva na sua plenitude. Afinal, os fatores de ausência de planejamento não são atribuídos à falta de conhecimento ou informação.

Além disso, especificamente a crise sanitária da pandemia COVID-19, que resultou, para além de mortes, desemprego e instabilidade econômica, na ausência do cuidado com o controle de finanças pessoais por parte das famílias, pode ter contribuído ainda mais com os reflexos do superendividamento das famílias.

Deste modo, a existência de projetos que atendam as diretrizes de educação financeira estabelecidas em lei não necessariamente são fatores diretos de mudanças profundas nas famílias brasileiras. As pesquisas realizadas pela Peic/CNC nos anos de 2013/2014; 2017/2018, embora indiquem melhorias no endividamento das famílias, podem ser tratadas como coincidência dos projetos postos no mapeamento, não sendo possível demonstrar uma ligação direta entre os resultados das pesquisas.

Essa consideração se justifica, pois embora o mapeamento demonstre os nomes dos projetos e os locais que foram desenvolvidos, não há registros de estudos específicos desses projetos e o impacto deles na alteração do estilo de vida familiar em relação ao cuidado orçamentário.

O que pode ser constatado é que diante do problema da ausência de educação financeira pessoal dos brasileiros, notase que o Brasil tem apresentado estratégias que visam promover a educação financeira, como também destacar a sua importância.

Nesse ponto, vislumbra-se o enquadramento da questão no modelo desenvolvido por Kingdon (2003), cujos fluxos foram preenchidos para tratar educação financeira no Brasil como política pública. Porém, na perspectiva do modelo do equilíbrio pactuado de Frank Baumgartner e Brian Jones (1993), a nova imagem apresentada pelo contexto da existência de projetos sobre educação financeira não foi suficiente para ensejar uma ruptura do status quo, qual seja, a permanência e constância das variáveis do superendividamento, excesso de ofertas de serviços bancários e oferta de crédito.

Nesse cenário, verifica-se que o problema ante a falta de educação financeira continua a apresentar indicativos desfavoráveis. Para tanto, o fluxo de alternativas proposto em Kindgon (2003) pode ser repensado para que outras soluções a respeito desse problema sejam ofertadas. Os resultados sobre os mapeamentos demonstram apenas que existem estratégias com a finalidade de atender as diretrizes propostas para a educação financeira, mas quando confrontado com outros dados, nota-se que não há uma correlação direta entre a existência desses projetos com efetiva mudança comportamental.

Outra questão, é que os projetos registrados no cadastro nacional não são objetos de análise específica, sendo o site governamental visto como um panorama do que o Estado propicia à sociedade nesse sentido. As pesquisas da Peic/CNC são focadas na questão do endividamento de famílias e nas causas desse endividamento. Assim, não apresentam resultados para além desse contexto.

Como visto, o Brasil possui estratégias para proporcionar ao brasileiro acesso à educação financeira, sobretudo a partir do marco regulatório do ano de 2010 revogado por novo decreto no ano de 2020. Todavia, a existência formal das estratégias ainda não é capaz de refletir os aspectos práticos da situação.

\section{Considerações Finais}

Tendo em vista a discussão ora apresentada, é possível perceber, de modo geral, que as pesquisas a respeito da 
educação financeira ainda estão restritas a determinadas áreas. Embora haja um crescente material a respeito dos seus conceitos, importância e fatores de implementação, os estudos sobre projetos de desenvolvimento de educação financeira ainda são raros.

O estabelecimento de diretrizes básicas de educação financeira por meio de decreto federal foi uma das soluções encontradas no fluxo de alternativas para tratar da problemática. Com o estabelecimento da norma, foi vislumbrado o desenvolvimento de projetos com vistas à conscientização da sociedade sobre o assunto.

Os mapeamentos realizados no site Vida e Dinheiro do Governo Federal nos anos de 2013 e 2018 apresentam um bom quantitativo de iniciativas, embora sejam poucas quando comparadas à extensão territorial e número da população brasileira. Contudo, os relatórios publicados apresentam o panorama geral desses projetos. Isso significa que não há como analisar cada trabalho registrado no site. Portanto, não é possível concluir qual a dimensão de eficácia desses trabalhos, isto é, o quanto sua existência é efetivamente alcançada pelos membros da sociedade.

Alinhado à essa consideração, as pesquisas no âmbito da Confederação Nacional de Comércio de Bens, Serviços e Turismo têm apresentado resultados constantes sobre o aumento exponencial do endividamento das famílias, como também o aumento daqueles que não irão quitar com as obrigações assumidas.

Nesse sentido, a pesquisa divulgada pela CDL em parceria com o Banco Central e outros parceiros apresenta que a ausência de conhecimento sobre educação financeira não é o fator principal que deixam os indivíduos nessa situação. Desse modo, o fluxo de alternativas proposto no modelo de múltiplos fluxos precisa de novas possibilidades para que a política pública sobre educação financeira seja efetivamente realizada. Nota-se que, nos termos do modelo de Frank Baumgartner e Brian Jones (1993), a situação se apresenta estabilizada com o seguinte status quo: "embora possamos ter conhecimento sobre o assunto, ainda não aplicamos na prática”. Portanto, uma nova mudança incremental a fim de romper esse quadro precisa ser pensada.

Portanto, os projetos desenvolvidos para atender as diretrizes de educação financeira no Brasil não são suficientes, por si só, para colaborar com a mudança comportamental dos indivíduos frente ao cuidado com o orçamento familiar.

Além disso, a presente pesquisa encontra limitações, pois os resultados das pesquisas realizadas pelo governo federal são genéricos. Não há divulgação exata do número de entrevistados e nem apresentação de maiores variáveis dos motivos pelos quais a ausência de controle financeiro se justifica, sendo estes expostos de forma tímida. Outro ponto, é que os projetos cadastrados com vistas a promover conscientização sobre educação financeira no Brasil não possuem estudos de viabilidade ou estudos específicos que apresentem os resultados dessas iniciativas, o que torna difícil realizar análises comparativas.

Espera-se que a reflexão desse trabalho possa estimular novas pesquisas, sobretudo para investigar projetos específicos de educação financeira no Brasil e seus resultados. Além disso, espera-se também contribuir com discussões sobre a educação financeira no plano nacional e principalmente reforçar a necessidade que a temática tem em ser tratada como política pública. O desafio consiste em estimular estudos para além do campo teórico.

\section{Referências}

Almeida, L. A., \& Gomes, R.C. (2017). Processo das políticas públicas: revisão de literatura, reflexões teóricas e apontamentos para futuras pesquisas. Cadernos EBAPE.BR, 16 (3), 444-455. doi: https://doi.org/10.1590/1679-395164108

Brito, L. S., Baptista, J. A., Silva, S. R., Braz, S., \& Henrique, M. R. (2012). A importância da educação financeira nos contextos acadêmicos e profissional: um levantamento de dados com alunos universitários. Anais do IX SEGeT-Simpósio de Excelência em Gestão e Tecnologia, 1-13.

Capella, A. C. N. Perspectivas teóricas sobre o processo de formulação de políticas públicas (2007). In Políticas Públicas no Brasil. Organizado por Gilberto Hochman, Marta Arretche e Eduardo Marques. Rio de Janeiro: FIOCRUZ, pp. 87-122. 
Cordeiro, N. J. N., Costa, M. G. V.,\& Silva, M. N. (2018). Educação Financeira no Brasil: uma perspectiva panorâmica. Ensino da Matemática em Debate, 5 (1), 69 - 84. doi: https://revistas.pucsp.br/index.php/emd/article/view/36841

Cruz, C. A. B., Santana, M. D. J., Silva, I. G., \& Santos, L. J. (ano). Mapeamento da produção científica relacionada à educação financeira. Revista Expressão Científica, 5 (2), 51-55. doi: https://aplicacoes.ifs.edu.br/periodicos/index.php/REC/article/view/523

Decreto Federal n 7.397 de 22 de dezembro de 2010. Brasília. Recuperado em 24 de abril de 2021.

Decreto Federal no 10.393 de 09 de junho de 2020. (2020). Brasília. Recuperado em 24 de abril de 2021.

Estratégia Nacional de Educação Financeira (2019). https://www.vidaedinheiro.gov.br/ .Recuperado em 26 de abril de 2021.

Ferreira, J. C. (2017) Caderno de Administração. Caderno de Administração. Revista do Departamento de Administração da FEA. Pontifícia Universidade Católica de São Paulo.

Gil, A. C. (2002). Como elaborar projetos de pesquisa 4. ed. São Paulo: Atlas.

Gottems, L. B. D., Pires, M. R. G. M., Calmon, P. C. D. P., \& Alves, E. D. (2013). O modelo dos múltiplos fluxos de Kingdon na análise de políticas de saúde: aplicabilidades, contribuições e limites. Saúde Soc. v.22, n.2, p.511-520

Leite, E. S. (2017). A ressignificação da figura do especulador-investidor e as práticas de educação financeira. Civitas. Porto Alegre, v. 17, n. 1, jan./abr., 114130. | doi: http://dx.doi.org/10.15448/1984-7289.2017.1.24446

Lucci, C. R., Zerrenner, S. A., Verrone, M. A. G., \& Santos, S. C. (2010). A Influência da Educação Financeira nas Decisões de Consumo e Investimento dos Indivíduos. Anais do $9^{\circ}$ SEMEAD, 2-10.

Neves, J. L. (1996). Pesquisa qualitativa - características, usos e possibilidades. Caderno de Pesquisa em Administração, São Paulo, V. 1, nº 3.

OECD. (2005). Improving financial literacy: analysis of issues and policies. Paris: Organization for Economic Cooperation and Development

Oliveira, F. G. M. de. (2020). Superendividamento do consumidor. Cadernos Jurídicos Da Faculdade De Direito De Sorocaba, 2 (1), 268-304. doi: https://www.fadi.br/revista/index.php/cadernosjuridicos/article/view/60

Pereira A. S. et al. (2018). Metodologia da pesquisa científica. [free e-book]. Santa Maria/RS. Ed. UAB/NTE/UFSM.

Saraiva, C.S. (2017). Os sujeitos endividados e a Educação Financeira. Educar em Revista [online], 66, 157-173. doi: https://revistas.ufpr.br/educar/article/view/53867

Savoia, J. R. F., Saito, A. T., Santana, Flávia de Angelis. (2007). Paradigmas da Educação Financeira no Brasil. Revista de Administração Pública - RAP, Rio de Janeiro 41(6): 1121-41. Nov./Dez., 1121-1141. | doi: 10.1590/s0034-76122007000600006

Scopel, D. C., \& Santos, E. O. (2020). A educação cooperativa como gerador de mudanças sociais: um estudo sobre a $6^{\text {a }}$ Semana da educação financeira na cidade de Itamaraju/BA. Revista de Gestão e Organizações Cooperativas - RGC. 7 (edição especial), 146-160. doi: https://doi.org/10.5902/2359043241725

Silva, C.C., Rodrigues, M. P. S., Moura, J. A., \& Castro, W. A. (2019). Financial Education: A study involving the students of a higher education institution of the city Divinopolis in Minas Gerais. Res., Soc. Dev. 8 (8). | doi: 10.33448/rsd-v8i8.1177

Silvestre, H. C, \& Araújo, J.F.F.E. (2015). Teoria do Equilíbrio Pontuado nas Políticas Públicas Brasileiras: O Caso do Ceará. RAC, 19 (6) 696-711. doi: $10.1590 / 1982-7849$ rac20151721

Souza, C. (2006). Políticas públicas: uma revisão da literatura. Sociologias, 8 (16), 20-45. doi: https://doi.org/10.1590/S1517-45222006000200003 